\title{
Understanding the processes that regulate positive emotional experience: \\ Unsolved problems and future directions for theory and research on savoring
}

\author{
Fred B. Bryant · Erica D. Chadwick · Katharina Kluwe
}

\begin{abstract}
In this paper, we focus on unanswered questions and future directions in positive psychology, with a special emphasis on savoring processes that regulate positive emotions. To advance our understanding of the savoring processes underlying positive experience, we highlight three unresolved issues that must be addressed: (1) discriminating the distinctive neuropsychological profiles associated with different savoring processes; (2) developing viable methods of measuring and analyzing the mediational mechanisms involved in real-time savoring; and (3) clarifying the developmental processes through which people acquire different strategies to savor positive experiences across the life span. We propose several potentially fruitful lines of attack aimed at addressing these unsolved problems, each of which requires new methods of assessment to advance theory and refine our conceptual understanding of savoring.
\end{abstract}

Keywords: positive psychology, savoring, neuropsychological profiles, mediation, development, emotion, wellbeing, well-being

\section{Introduction}

Psychologists are yet to fully address the vast richness and complexity of positive experience. In studying positive emotional experience, theory and research in psychology has focused primarily on the affective consequences of positive events as a function of situational and personal characteristics. Although that work provides useful predictive models for distinguishing levels and types of emotional reactions to positive events, it has only recently begun to explore the causal mechanisms through which positive experiences produce different emotional reactions in different individuals or within the same individual over time.

We currently know very little about how the mind transforms positive and negative experiences into emotions. What positive psychology currently lacks is a clear understanding of the mediational processes through which positive events produce particular emotions. The purpose of this paper is to address crucial obstacles that theorists and researchers must surmount in order to develop a clearer understanding of the processes that regulate positive emotional experience.

We begin by briefly reviewing current conceptual perspectives on savoring as a diverse set of processes underlying the regulation of positive feelings. Having provided a theoretical framework for understanding savoring, we then consider three important unsolved problems concerning savoring processes and the mechanisms through which they unfold-puzzles that 
must be resolved in order to advance our understanding of the savoring processes underlying positive experience. These thorny problems are: (1) discriminating the distinctive neuropsychological profiles associated with different savoring processes; (2) developing viable methods of measuring and analyzing the mediational mechanisms involved in real-time savoring; and (3) clarifying the developmental stages, and concomitant changes in cognitive and social skills and in life experiences, that underlie the acquisition of different savoring strategies across the life-span. We address each of these critical issues in turn and propose several potentially fruitful lines of attack aimed at addressing these unsolved problems.

\section{Current perspectives on savoring}

Savoring involves the self-regulation of positive feelings, most typically generating, maintaining, or enhancing positive affect by attending to positive experiences from the past, present, or future (Bryant, 1989, 2003; Bryant, Ericksen, \& DeHoek, 2008; Bryant \& Veroff, 2007). In explicating the nature of savoring, it is important to distinguish four interrelated conceptual components: savoring experiences, savoring processes, savoring strategies, and savoring beliefs. At the broadest conceptual level, a savoring experience consists of one's sensations, perceptions, thoughts, behaviors, and feelings when mindfully attending to and appreciating a positive stimulus. Examples of savoring experiences include listening to a virtuoso musical performance, eating a gourmet meal, soaking in a warm bath, receiving a compliment, spending time with a good friend, or winning an honor or award. At an intermediate conceptual level, a savoring process is a sequence of mental or physical operations that unfolds over time and transforms a positive stimulus into positive feelings to which a person attends and savors. At the narrowest conceptual level, a savoring response or strategy is the operational component of the savoring process - that is, a specific concrete thought or behavior that amplifies or dampens the intensity, or prolongs or shortens the duration, of positive feelings. Examples of savoring responses or strategies include counting blessings to remind oneself of one's good fortune, carefully taking a "mental photograph" of a spectacular sunset for later recall, mentally congratulating oneself in response to a personal achievement, and closing one's eyes to focus one's attention and block out distractions while tasting a delicious wine. And lastly, savoring beliefs reflect people's perceptions of their ability to enjoy positive experiences, as distinct from their ability to obtain positive outcomes in the first place, and encompass temporal domains of savoring (Bryant, 2003; Bryant et al., 2008; Bryant \& Veroff, 2007).

\subsection{Savoring experiences}

Bryant and Veroff (2007) distinguished savoring experiences in terms of whether one's dominant focus of attention is on the external world or the internal self during the savoring experience. In world-focused savoring, the source of positive feelings is primarily identified with something or someone outside oneself (e.g., being awestruck by a spectacular sunset). In such experiences, savoring is largely experienced as an involuntary, uncontrollable positive emotional response to an external stimulus. In self-focused savoring, on the other hand, positive feelings are primarily perceived as originating within the self (e.g., pride in winning a contest). Bryant and Veroff (2007) also further distinguished savoring experiences in terms of whether they primarily involve cognitive reflection, in which one introspects about one's subjective experience, or experiential absorption, in which one minimizes introspection in favor of perceptual engrossment (see Lambie \& Marcel, 2002). 


\subsection{Savoring processes}

Different savoring processes are presumed to regulate different positive emotional states (Bryant \& Veroff, 2007). For example, the savoring process of: (a) thanksgiving regulates gratitude, (b) marveling regulates awe, (c) basking regulates pride, and (d) luxuriating regulates physical pleasure. Combining the distinctions between world- versus self-focused attention and between reflection versus absorption with respect to savoring experiences produces a $2 \times 2$ classification model of four primary savoring processes and their associated positive feelings (see Figure 1 below): (a) the savoring process of thanksgiving (which underlies gratitude) is a form of world-focused cognitive reflection; (b) the savoring process of marveling (which underlies awe) is a form of world-focused experiential absorption; (c) the savoring process of basking (which underlies pride) is a form of self-focused cognitive reflection; and (d) the savoring process of luxuriating (which underlies physical pleasure) is a form of self-focused experiential absorption.

\section{Focus of Attention}

\section{Type of Experience}

Cognitive Reflection

Experiential Absorption

\begin{tabular}{ccc}
\hline External World & & Internal Self \\
$\begin{array}{c}\text { Thanksgiving } \\
\text { (gratitude) }\end{array}$ & & $\begin{array}{c}\text { Basking } \\
\text { (pride) }\end{array}$
\end{tabular}

Luxuriating (physical pleasure)

Figure 1. Conceptual model of four primary savoring processes and the positive affective states associated with them, as a function of focus of attention and type of experience (adapted from Bryant \& Veroff, 2007).

\subsection{Savoring strategies}

Bryant and Veroff (2007) have identified ten savoring strategies that people use in relation to positive experience: Sharing with others, memory building, self-congratulation, sensoryperceptual sharpening, comparing, absorption, behavioral expression, temporal awareness, counting blessings, and kill-joy thinking. Just as different cognitive appraisals predict the use of different coping strategies, likewise different cognitive appraisals predict the use of different savoring strategies. For example, stronger internal causal attributions for a positive outcome predict higher levels of self-congratulation, greater perceived outcome rarity predicts greater memory building, and greater perceived event desirability predicts greater use of counting blessings. Women, compared to men, tend to engage more in sharing with others, behavioral expression, and counting blessings (all of which are associated with greater enjoyment) in response to positive outcomes, whereas men tend to report a greater use of kill-joy thinking (which is associated with less enjoyment).

Although Bryant and Veroff (2007) originally categorized savoring strategies in terms of whether these responses reflected cognitive processes (e.g., self-congratulation), behavioral processes (e.g., behavioral expression), or a blend of both cognitive and behavioral processes (e.g., sensory-perceptual sharpening), subsequent theorists have used other conceptual 
frameworks for categorizing savoring strategies. For example, Chadwick and Jose (2010) have categorized different savoring responses as reflecting either engaged savoring (e.g., absorption) or dismissive savoring (e.g., kill-joy thinking). Others have distinguished between savoring responses intended to amplify positive emotion and dampening responses intended to suppress positive emotion (Wood, Heimpel, \& Michela, 2003). Extending this latter framework, Quoidbach, Berry, Hansenne, and Mikolajczak (2010) have distinguished among four broad types of savoring strategies (behavioral display, focusing attention on the present moment, capitalizing, and positive mental time travel) and four broad types of dampening strategies (suppression, fault finding, distraction, and negative mental time travel).

In contrast, Bryant and Veroff (2007) considered both amplifying and dampening responses to be efforts to regulate positive emotions that reflect different styles of savoring. For example, the cognitive savoring strategy of "kill-joy thinking," which stifles positive feelings, is more prevalent among East Asian adults than North American adults (Bryant \& Veroff, 2007) and serves to regulate positive emotions in ways that are culturally normative. By the same token, efforts to cope by "catastrophizing" one's situation actually amplify distress, but are nonetheless conceptualized as coping responses (Keefe, Brown, Wallston, \& Caldwell, 1989).

These multiple conceptual frameworks of savoring strategies parallel the wide range of theoretical models for categorizing coping strategies, including distinctions between cognitive versus behavioral coping (Moos \& Schaefer, 1991), problem-focused versus emotion-focused coping (Lazarus \& Folkman, 1984), active versus passive coping (Brown \& Nicassio, 1987), and approach versus avoidance coping (Roth \& Cohen, 1986). Operationalizing Bryant and Veroff's (2007) notion of complexity in savoring responses, Quoidbach et al. (2010) have also focused on the concept of positive regulatory diversity (i.e., using multiple savoring strategies rather than a few specific savoring strategies) and have found that people who typically use a broader range of savoring strategies report higher levels of overall happiness.

\subsection{Savoring beliefs}

Bryant (2003) developed the Savoring Beliefs Inventory (SBI) as a self-report instrument for assessing savoring beliefs with respect to savoring the moment, savoring through reminiscence, and savoring through anticipation. Although a savoring experience requires a focus of attention on positive feelings in the present, savoring may also involve a temporal focus on either the past (termed reminiscence) or the future (termed anticipation). When people savor through reminiscence, they attend to positive feelings that they rekindle from the past, or attend to other positive feelings they experience when looking back on the past. When people savor through anticipation, they attend to positive feelings they imagine they will have in the future, or attend to other positive feelings they experience when looking forward. People may also enhance the quality of an unfolding positive experience by remembering how much they looked forward to it earlier (i.e., recalled anticipation) or by looking forward to reminiscing about it later (i.e., anticipated recall). Regardless, the positive feelings that one experiences when savoring are in the here-and-now. Thus, savoring can involve a form of "mental time travel" (Quoidbach et al., 2010; Suddendorf \& Corballis, 2007), through which individuals either generate positive feelings in the present from imagining future or past positive events, or enhance the emotional impact of ongoing present events by reflecting on them from a past- or future-focused perspective.

With both an adult and child version of the SBI, Bryant and Veroff (2007) discuss how females, compared to males, tend to perceive themselves as more capable of savoring positive experiences - a sex difference that emerges as early as 10 years of age, persists throughout older 
adulthood, and has been found in the United States, Canada, Australia, and Japan (Bryant \& Veroff, 2007). Comparing SBI scores across temporal domains within individuals, people typically report that they are most capable of savoring through reminiscence, moderately capable of savoring the moment, and least capable of savoring through anticipation.

Having provided a conceptual overview of savoring, we now consider three unresolved problems that theorists and researchers in this area face. These are scientific challenges that must be overcome in order to advance our understanding of savoring. For each of these issues, we discuss the current state of knowledge in the social and behavioral sciences with respect to the underlying matters, and we suggest ways in which future work might approach the problem.

\section{Clarifying the neuropsychological underpinnings of savoring}

One thorny unaddressed problem in understanding savoring involves determining whether different savoring processes have unique neuropsychological underpinnings and, if so, discriminating the distinctive neurological profiles associated with each process. For instance, one might hypothesize that each of the four primary savoring processes - thanksgiving, marveling, basking, and luxuriating - is associated with a unique pattern of brain activity involving the operation of different neural mechanisms. However, relatively few studies have systematically explored the neuropsychology of positive emotion (Borod, 2000; Burgdorf \& Panksepp, 2006; Phan, Wager, Taylor, \& Liberzon, 2004), and none as yet have explicitly investigated the neuropsychology of savoring.

Because the field of positive neuropsychology is still in its infancy, we have much to learn about the neuro-anatomy of enjoyment. Indeed, neuroscientists have yet to determine how positive affect arises in the brain (Burgdorf \& Panksepp, 2006; Kringelbach \& Berridge, 2009). If savoring through attentional focus on positive feelings is truly distinct from pleasure per se, however, then neurological activity during savoring experiences should be noticeably different from neurological activity during simple pleasure. Along these lines of establishing distinctions among positive neuropsychological processes, Kringelbach and Berridge (2009) have proposed that eudaimonia (i.e., the experience of purpose or meaning) is associated with a distinctive neurological profile compared to hedonia (i.e., the experience of pleasure or joy). Unfortunately, however, researchers have not yet focused systematically on the neuropsychology of savoring.

\subsection{Differences in emotional reactions to negative and positive experience}

Prior research aimed at differentiating brain regions and processes related to negative and positive experience and emotion has established the foundation for research on positive neuropsychology. Brain-imaging studies indicate that unpleasant stimuli activate an older, more primitive part of the human brain, whereas pleasant stimuli activate a higher order part of the human brain of more recent evolutionary origin (Hamann, Ely, Hoffman, \& Kilts, 2002; Paradiso et al., 1999). Consistent with these findings, MacLean (1990) suggested that negative experience primarily engages the older, primitive "reptilian brain," whereas positive experience primarily engages the younger, executive functioning "mammalian brain."

Other neuro-imaging research has demonstrated that self-generated positive experiences produce a different neuro-anatomical profile than do self-generated negative experiences. For example, Damasio et al. (2000) instructed 41 adults (age 24-42) to re-experience intense personal emotional episodes involving happiness, sadness, anger, or fear, and to recall an equally specific but emotionally neutral episode involving an unemotional but specific day (from getting up in the morning to preparing breakfast, getting dressed, leaving for work, 
arriving at work, and continuing on throughout the day). Participants were encouraged to produce detailed images of recalled events and to concentrate attentively on those images. Positron emission tomography (PET) scanning revealed that reliving past experiences of happiness produced a different pattern of neurological activity than did reliving past experiences of sadness, anger, or fear. These findings suggest that the process of mentally reliving positive experiences, as through retrospective savoring, is neurologically distinct from the process of mentally reliving negative experiences, as through rumination.

There is also evidence that the anticipation of joy activates a different region of the brain than the anticipation of punishment. For instance, Knutson, Adams, Fong, and Hommer (2001) obtained functional magnetic resonance imaging (fMRI) scans from eight adults as these individuals anticipated either winning or losing money while playing a video game. Results revealed that anticipated reward activated the sub-cortical nucleus accumbens and elevated self-reported happiness, whereas anticipated punishment did not. These findings support the conclusion that looking forward to positive experiences stimulates parts of the brain associated with appetitive stimuli more than do other forms of anticipation.

\subsection{Positive neuropsychology}

Contemporary neurological evidence reveals that when people contemplate positive stimuli, the brain actively perceives the way in which the body responds to these stimuli. For example, Matsunaga et al. (2009) used PET scanning to compare the neurological reactions of 12 healthy male volunteers (age 20-29) to a film portraying romantic scenes involving marriage and expressions of love versus a neutral "control" film of a past TV weather report. Relative to the neutral film, the romantic film produced greater activation of the medial prefrontal cortex, thalamus, superior temporal gyrus, inferior frontal gyrus, and cerebellum; and these neurological changes were associated with heightened positive mood. Activities of brain regions related to interoceptive awareness (i.e., an individual's ability to discriminate between sensations and feelings), such as the insular cortex, anterior cingulate cortex, amygdala, and orbitofrontal cortex, were also linked temporally to increases in high-frequency heart-rate variability. These results suggest that while an individual experiences positive emotions, activities of the central nervous system and cardiovascular system are interrelated, such that the brain perceives the body to be in a positive state. Such findings support the conception of savoring as involving a cognitive meta-awareness of ongoing positive experience.

Electroencephalogram (EEG) measurements of brain electrical activity show that resting asymmetry predicts positive emotion; specifically, relative left hemispheric activity is related to positive emotion (Tomarken, Davidson, Wheeler, \& Doss, 1992; Tomarken, Davidson, \& Henriques, 1990). Researchers suggest that the brain systems represented by frontal EEG asymmetries are moderators of emotional activity, or, in the case of emotional activation, mediators (Coan \& Allen, 2004). These frontal asymmetries are proposed to reflect brain systems that mediate approach and withdrawal motivational tendencies underlying emotional responding, in other words, processes within the savoring experience. Only recently has the EEG method of measurement been used to reveal second-by-second variations in the experience and expression of pleasure (Light, Coan, Frye, Goldsmith, \& Davidson, 2009). Children, ages 6 to 10 years old, who expressed increasing pleasure by smiling, and vocally, facially and/or physically expressing positive affect, showed increases in left frontal activity while playing a game. Children who expressed contentment showed increases in right frontal activity and decreases in left frontal activity. This study indicates that asymmetry may be more 
than an indicator of approach-withdrawal driven motivations; namely it may signal externalinternal focus as well.

Other recent research provides evidence that different types of positive experiences involve different neurological processes. For example, Takahashi et al. (2008) instructed 16 college students to imagine experiencing events involving either joy (e.g., winning a lottery, eating a favorite food, going on a date), pride (e.g., getting a perfect score on a math test, winning a sports competition, winning first place in a music recital), or neutral affect (e.g., recording a TV show, studying, buying medicine for a cold) while undergoing fMRI. Results indicated a different pattern of brain activity during imagined experiences of pride versus joy. Pride conditions produced greater activity in the middle temporal gyrus and left temporal pole, which are components of neural substrates associated with social cognition (Adolphs, 2001). Joy conditions, in contrast, produced greater activity in the ventral striatum including the nucleus accumbens, which are key nodes for processing hedonic and appetitive stimuli (Rolls, 2006). These findings are consistent with the notion that the savoring process of luxuriating in appetitive stimuli, such as food or gifts, involves different neurological correlates than the savoring process of basking in the pride of accomplishment.

Additional fMRI research suggests that re-experiencing past events and pre-experiencing future events both activate a common neurocognitive system involving the joint contribution of medial temporal and medial prefrontal structures, including areas of the brain involved in selfreferential processing, dissociation from one's current state, and cognitive elaboration (Addis, Wong, \& Schacter, 2007; Botzung, Denkova, \& Manning, 2008). Thus, savoring through reminiscence may well engage some of the same areas of the brain as does savoring through anticipation. However, compared to imagining future events, recalling past experiences appears to activate the medial pre-frontal cortex more strongly (Botzung et al., 2008)-results consistent with neurological studies of episodic, autobiographical memory.

\subsection{Savoring and positive neuropsychology}

Future work in positive neuropsychology is needed to explore how brain activity differs when people are savoring different types of positive experiences. In general, because savoring is meta-cognitive, we hypothesize that all savoring experiences activate the prefrontal cortex, although to varying degrees depending on the specific type of savoring experience involved. Based on current theory and research in neuropsychology, we can speculate about differences in neurological activity that are likely to underlie several different forms of savoring. See Figure 2 (next page) for a summary of the brain regions we speculate are associated with savoring.

For instance, we expect savoring that involves cognitive elaboration will activate cortical regions of the brain, in contrast to savoring that involves more passive processes such as experiential absorption, which will activate subcortical regions (Woltering \& Lewis, 2009). Cognitive elaboration requires higher-order executive functioning, and thus places greater demands on the prefrontal cortex, while experiential absorption more exclusively taps reward and pleasure regions. Recognizing that the reward system involves the prefrontal cortex and is highly complex, we adopt a reward circuitry for experiential absorption from Ikemto's (2010) neurobiological theory, which includes contributions from the nucleus accumbens, medial prefrontal cortex, and lateral hypothalamus. In addition, we propose that experiential absorption generally activates sensory systems for touch and vision in the parietal cortex more than does cognitive elaboration (Olivier, Pouget, \& Duhamel, 2005). 


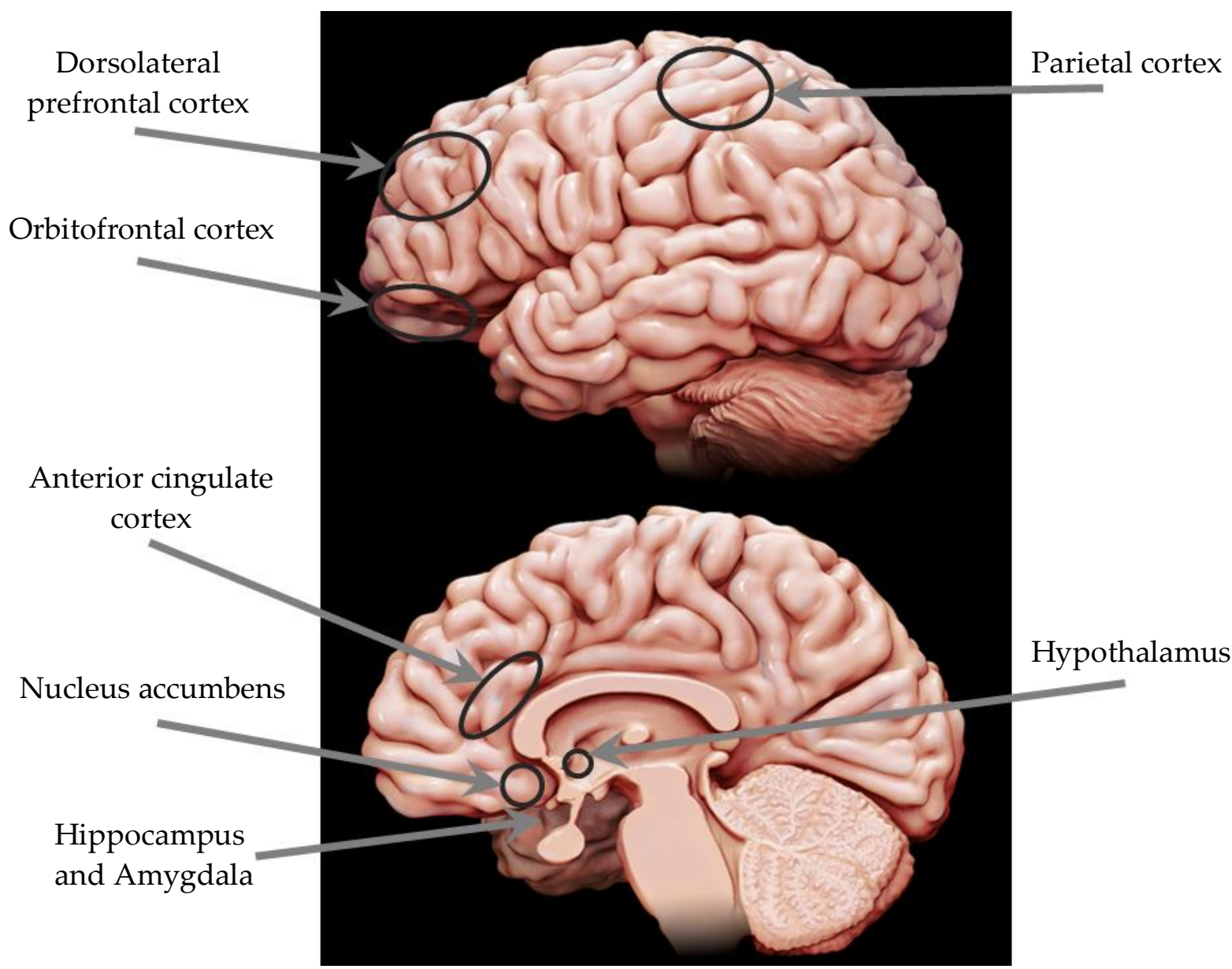

Figure 2. Summary of regions speculated to be associated with savoring.

(oAndrew Swift MS CMI (www.swiftillustration.com)

We can also speculate about the neurological correlates of self- versus world-focused savoring. Recent fMRI experiments reveal that being "strongly externally aware" correlates with activation of lateral fronto-parietal areas, whereas being "strongly internally aware" correlates with activation of medial brain areas (Vanhaudenhuyse et al., 2011). Because worldfocused savoring involves a heightened awareness of one's environment, we also propose that world-focused savoring activates regions in the hippocampus that represent the spatial environment (Moser, Kropff, \& Moser, 2008).

Finally, we can speculate about the brain regions involved in proactive versus reactive savoring. Because proactive savoring involves the executive functions of planning and organizing, we hypothesize that generating positive emotions "from scratch" will engage the dorsolateral prefrontal cortex, which regulates these particular higher-order functions (Lezak, Howieson, Loring, Hannay, \& Fischer, 2004; Woltering \& Lewis, 2009). In contrast, we expect reactive savoring to activate neural regions responsible for the regulation of reactive emotions, in particular the amygdala, hypothalamus, anterior cingulate cortex, and orbitofrontal cortex (Woltering \& Lewis, 2009).

However, several major procedural restrictions limit the utility of currently available MRI and PET scanners as tools for studying the neuropsychology of savoring. Because the quality of images is extremely sensitive to even small involuntary movement (e.g., breathing, swallowing, twitching), which can degrade clarity and produce image artifacts, current neuro-radiological technology requires research participants to remain motionless during scanning (Reiser, Semmler, \& Hricak, 2008). Obviously, such restrictions may alter people's natural and 
spontaneous savoring responses, distract their attention while trying to savor, or prevent them from savoring in ways that are behaviorally expressive. Another problem is that while undergoing MRI, people often experience anxiety-related reactions, ranging from tension to claustrophobia to panic attacks (Melendez \& McCrank, 1993), which not only compromise the quality of images, but also alter the very thoughts and feelings under investigation. Moreover, scanners currently cost millions of dollars, are difficult to access due to high demand, and are not feasible for collecting data in ongoing real-life situations. Obviously, major advances in scanning technology are necessary before researchers can use MRI and PET scanning to study the neuropsychology of spontaneous real-time savoring in naturalistic settings. These limitations make EEG measurement a promising technique for assessing the neuropsychology of real-time savoring.

Ultimately, a systematic understanding of the neurological underpinnings of savoring will support the development of pharmacological treatments aimed at boosting savoring capacity in individuals with specific forms of brain injury or disorder. Such work also has the potential to guide the development of cognitive-behavioral interventions aimed at improving quality of life for individuals who have lost the neurological capacity for certain forms of savoring, but who are still capable of savoring in other ways. Clearly, much work remains to be done in the uncharted areas of positive neuropsychology in general, and the neuropsychology of savoring in particular.

\section{Investigating mediational mechanisms in real-time savoring}

A second thorny problem in the study of savoring is the methodological challenge of studying the mediational mechanisms involved in real-time savoring. To tackle this problem, researchers must identify not only the duration and sequencing of relevant independent variables in real time, but must also develop reliable and valid methods and measurement procedures for categorizing and quantifying these key variables as they unfold in real time. These new methods must assess savoring in ways that do not alter the phenomena under investigation. Current retrospective self-report methods and measures are inadequate for studying ongoing savoring processes as they unfold in the moment and across real time. And yet, without such research, it is impossible to develop an ecologically valid psychology of savoring.

\subsection{Mediational effects}

Although the concept of mediation has a relatively long history in psychology (MacCorquodale \& Meehl, 1948), there has been a huge up-swell of interest in this topic during the past two decades (MacKinnon, Fairchild, \& Fritz, 2007). James and Brett (1984) defined mediation as the process by which the "influences of an antecedent are transmitted to a consequence through an intervening variable" (p. 307); and Baron and Kenny (1986) defined mediation as "the generative mechanism through which the focal independent variable is able to influence the dependent variable of interest" (p. 1173). Mediational analyses pinpoint causal chains of influence through which independent variables transmit effects to dependent variablesessential information in advancing our understanding of the dynamic processes that underlie psychological phenomena in both experimental and nonexperimental research (Holmbeck, 1997; Shrout \& Bolger, 2002; Spencer, Zanna, \& Fong, 2005).

The investigation of mediation has evolved from the initial study of a simple "two-step path sequence" (i.e., A $\rightarrow$ B $\rightarrow C$ ) via correlation and multiple regression into the analysis and comparison of multiple simultaneous indirect effects via path analysis and structural equation 
modeling (MacKinnon, 2000; Preacher \& Hayes, 2008). Techniques are also available for analyzing complex multilevel mediation in which indirect effects occur in clustered data that include both between-groups and nested within-subjects measurements in the same analysis (Preacher, Zyphur, \& Zhang, 2010). Researchers have now developed statistical procedures for testing the statistical significance of three-step path mediation, in which $A \rightarrow B \rightarrow C \rightarrow D$ (Taylor, MacKinnon, \& Tein, 2008). In addition, researchers have developed statistical procedures for testing interactional hypotheses about "moderated mediation" (Preacher, Rucker, \& Hayes, 2007), in which another independent variable influences the strength of a particular mediating mechanism, such that mediation is stronger under certain circumstances, for certain types of events, or for certain types of people, compared to others.

Within the context of research on savoring, mediational analyses provide a means of testing hypotheses about the specific causal mechanisms through which positive outcomes and events influence positive emotions. Different types of positive experiences presumably evoke different cognitive appraisals, which activate different combinations of savoring responses, which in turn produce different positive feelings. These savoring responses sometimes change the actual or perceived nature of the antecedent positive stimulus, thereby further modifying subsequent savoring responses (Lazarus \& Folkman, 1984). Thus, real-time savoring is assumed to unfold in a rich multiplicity of complex ways, which may well involve bidirectional causality. In many respects, current methods of studying and measuring savoring processes and their mediating effects on positive emotions are inadequate to accommodate these complexities. New methods are needed in order to investigate savoring as a dynamic process that unfolds in real time.

\subsection{A dynamic process: Causal ordering and the mediational effects of savoring}

Given a particular positive event, the same savoring responses arranged in different temporal orders might well produce different emotional consequences. And yet, prior cross-sectional and longitudinal research on savoring has ignored the temporal sequence in which multiple savoring responses may occur.

For instance, an awareness of the fleetingness of time may have a different impact on positive emotions depending on the exact timing of these thoughts during the savoring process. Research indicates that increased awareness of an experience's future ending can enhance one's present enjoyment of it (Kurtz, 2008). In particular, undergraduates instructed to think about college graduation about six weeks beforehand reported greater happiness, and made more efforts to capitalize on the remaining time they had left in college, when the time remaining until their graduation was framed as being short (one-tenth of a year) as opposed to long (1,200 hours). However, naturally-occurring thoughts about the fleetingness of time may well have profoundly different emotional consequences depending on the specific timing of such thoughts.

Consider two individuals, $\mathrm{Al}$ and Zack, both of whom are celebrating their birthday. Both individuals engage in the same two cognitive savoring responses during the celebrationnamely, each reminds himself how fast time is passing, and each thinks about how fortunate he is to be experiencing his birthday celebration - but in opposite sequential order. Al thinks first about how fast time is passing in his life, and then thinks how fortunate he is to be celebrating his birthday; whereas Zack, in contrast, thinks first about how fortunate he is to be celebrating his birthday, and then thinks about how fast time is passing in his life. Although both individuals engaged in the same two savoring responses during the birthday celebration, $\mathrm{Al}$ might well report greater positive affect and more gratitude than Zack, as a result of the different causal sequences for the same two savoring responses. Alternative temporal orderings 
of the same set of savoring strategies may produce dramatically different emotional consequences. This possibility highlights the critical importance of studying mediational primacy and recency effects for savoring responses as they unfold in real time, in order to understand the impact of savoring on positive emotions.

\subsection{Savoring: Unfolding in real time}

To assess subjective experience in real time, researchers have developed other self-report methods of assessment besides paper-and-pencil or online measures. For example, participants can use rotating dials or sliding meters to reflect their momentary feelings in real time (Larsen \& Fredrickson, 1999). Yet, such measurement strategies may be awkward or distracting, particularly in real-life settings. Indeed, there is evidence that continually evaluating one's own emotional states during a positive experience can lower one's final level of enjoyment, compared to simply rating one's feelings at the end of the experience (Schooler, Airely, \& Loewenstein, 2003). The process of assessing one's own thoughts and feelings may change the very experiences being evaluated.

Other work has developed alternative methods of assessing emotions that go beyond selfreport. For example, the frequency, intensity, onset, and duration of positive emotions can be quantified from specific observable changes in facial muscles using the Facial Action Coding System (Ekman \& Friesen, 1978). Extending this form of assessment, Bailenson et al. (2008) have developed and validated an automated, computer-driven real-time system for the recognition of emotion (including happiness) in videotapes of facial expressions in conjunction with physiological measurements of cardiovascular activity, somatic activity, and electrodermal responses. Yet, these methods of measurement have the drawbacks of reactivity, cost, and difficulty of implementation in real-world settings.

To assess mediational processes involving cognitive appraisals, savoring responses, and positive emotions in real time in a less reactive fashion that is more feasible in real life, participants could be asked to vocalize their thoughts and feelings while they are occurring, and the content, sequencing, intensity, and duration of these verbal expressions could be coded and analyzed via process-tracing methods such as verbal protocol analysis (Ericsson \& Simon, 1993). Researchers could also use a variation of the Electronically Activated Recorder (Mehl, Vazire, Holleran, \& Clark, 2010) - a digital audio device that unobtrusively records ambient sounds while participants go about their daily lives - to apply processing-tracing methods to real-time verbal protocols during ongoing savoring experiences. Cowie and Cornelius (2003) have reviewed methods, tools, and coding systems currently available for quantifying the emotional states conveyed in human speech. A top priority for future research on real-time savoring processes is to refine the measurement tools and scoring systems required to assess savoring during ongoing positive experiences.

\section{Identifying the life-span developmental mechanisms for learning to savor}

Besides unanswered questions about neuropsychological underpinning and mediational mechanisms in real-time savoring, a third unsolved problem in work on savoring is the need to clarify the processes through which people learn to use different cognitive and behavioral strategies to savor positive experience across the lifespan. Children's capacity to regulate positive emotions evolves over the course of neurophysical and cognitive development. In addition, the dispositional influences of temperament and personality limit the range and characteristic levels of positive affect children experience, and make it easier or harder for them to savor in particular ways. Environmental factors also shape the repertoire of savoring 
responses that children acquire over time, through family dynamics, social and peer relations, and cultural influences (Bronfenbrenner \& Morris, 2005). The natural course of aging changes cognitive and behavioral capacities for savoring among older adults. A great unrealized challenge is to identify the life-span developmental stages and processes through which children and adults adopt, expand, and revise their savoring repertoire in relation to positive experiences throughout life. It is also important to discover how savoring may shape development through social relationships, lifestyle, and health.

Within the prescriptive bounds of culture, families directly and indirectly encourage or discourage the active pursuit of positive experience in children through the ways in which they organize children's experiences. For example, whether or not parents celebrate milestones, birthdays, holidays, and accomplishments, take vacations, and pursue enjoyment at work and leisure-and the specific ways in which they do so-not only teaches children the value of appreciating and enjoying life, but also provides concrete models for savoring that children can imitate. Moreover, the process of socialization produces lifelong frameworks or schemas for approaching certain forms of positive experience in specific ways (Tomkins, 1962).

\subsection{Savoring the moment}

Young children, even infants, seemingly have an innate capacity for positive feelings. Between 6 and 8 weeks, smiles of enjoyment occur in response to visual, auditory, and tactile stimulation, and expressions of enjoyment in response to social stimuli increase dramatically by 4 months of age (Sullivan \& Lewis, 2003). Early in life, caregivers promote and regulate positive emotions and guide the development of self-referent positive emotions in children, through selective reinforcement and modeling of emotional behavior (Tronick, Cohn, \& Shea, 1986). One arena in which caregivers first encourage and regulate children's positive affect is during parent-child play, in which parents deliberately enhance or dampen their child's emotional reactions to maintain an optimal level of arousal (Stern, Hofer, Haft, \& Dore, 1985). Imaginative play may well provide the earliest structured proving-ground where children can experience self-control over positive emotions (Hughes, 2010).

Parents also influence the development of emotional regulation by the nature of the living situation they provide, stemming from their personality, socioeconomic status, values, and cultural norms, among other influences. But over time, children become more capable of selfregulating positive emotions as a function of neurophysiological development, the acquisition of cognitive and linguistic skills, and increased self-understanding. The development of children's language skills is also crucial in the development of savoring because it enables caregivers to communicate verbally with children about the causes and consequences of positive emotions, the rules for public expression of positive affect, the benefits of regulated emotions, and concrete strategies for generating, intensifying, dampening, sustaining, or curtailing positive feelings. In addition, children overhear and understand when their parents talk about their own emotional experiences and learn to imitate their cognitive and behavioral repertoires (Thompson, 1991).

As cognitive development continues during the preschool years, representational skills related to emotion emerge, providing children with "meta-emotive understanding," or concrete knowledge of emotional processes (Thompson, 1990), which are the basis for the child's first conscious strategies for managing emotions. Younger preschool children typically have only a few simple, predominantly behavioral strategies for regulating emotions, such as controlling sensory inputs by covering the eyes or ears (Bretherton, McNew, \& Beeghly-Smith, 1981) or physically relocating themselves. This fact suggests that behavioral savoring strategies such as 
sensory-perceptual sharpening, experiential absorption, and behavioral expression may be the earliest techniques that children acquire for enhancing positive feelings. During middle childhood, the range and complexity of strategies for managing emotion increase dramatically, as children learn that they can alter emotions by redirecting their attention (Harris \& Lipian, 1989), controlling their own thoughts (Carroll \& Steward, 1984), or reinterpreting the situation to amplify or dampen their arousal (Terwogt, Schene, \& Harris, 1986). If the development of savoring parallels that of coping, then cognitive savoring responses develop in late childhood. Research indicates that young children cope with stress using behavioral distraction methods such as playing with favorite toys, whereas older children are more likely to use cognitive strategies such as imagining pleasant fantasies (Band \& Weisz, 1990; Compas, 1998).

\subsection{Savoring through reminiscence}

Children as young as three years of age can accurately describe details of events that occurred several months earlier (Reese, Haden, \& Fivush, 1993). And by the end of the preschool years, children can narrate their own past experiences to others, regardless of whether their audience has shared those experiences (Fivush, Haden, \& Reese, 1996). By age 6, children also understand that people can rekindle emotion by recalling memories of an earlier emotional experience (Harris, Guz, Lipian, \& Man-Shu, 1985). However, it is important to keep in mind that savoring the past is a higher-order process than simply recalling the past. No one has yet studied systematically the extent to which children deliberately savor by looking back on positive memories, and the age at which they typically first begin to do so.

Savoring through reminiscence requires one to reflect on feelings associated with pleasant memories and to think abstractly about one's own inner experience. Based on evidence that the higher-order cognitive functions necessary to engage in past-focused self-reflection may not fully develop until late childhood or early adolescence (Inhelder \& Piaget, 1958), Bryant and Veroff (2007) proposed that children gradually learn through socialization to articulate their inner experience in relation to the past. In particular, children presumably first master the art of retelling and reliving positive memories in the company of others and then later learn how to savor positive memories in their mind when they are developmentally capable of such abstractions.

\subsection{Savoring through anticipation}

At least three cognitive skills are necessary in order to savor by looking forward to positive experiences - an ability to reflect on one's own feelings, an awareness of the future, and the capacity to delay gratification. As early as age 2, children show awareness of the future in their speech and behavior (Atance \& O'Neill, 2001). However, children typically do not develop the cognitive resources and perspective-taking skills necessary to delay gratification until age 4 or 5 (Mischel, Shoda, \& Rodriguez, 1989). Not surprisingly, this lack of impulse control makes it hard for young children to savor upcoming positive experiences through anticipation. Indeed, adults often find it difficult to delay gratification in certain situations, making savoring through anticipation a lifelong challenge.

Further complicating the process of anticipation are the possibility of disappointment and the necessity of coping with dashed hopes and expectations. Through socialization, children typically learn the effortful control required to handle disappointment; mothers' strategies for regulating their children's emotions at age $2 \frac{1}{2} 2$ predict these children's facial and behavioral responses to disappointment at age 5 (Spinrad, Stifter, Donelan-McCall, \& Turner, 2004). The potential for positive anticipation to produce unrealistically high expectations and to inflate the 
perceived likelihood of positive outcomes also makes future-focused savoring a greater challenge than past-focused savoring. To protect children from the pain of disappointment if the future outcome does not happen or fails to meet expectations, some parents may teach their children not to "get their hopes up" or not to "count your chickens before they hatch." Although such forms of defensive pessimism may temper disappointment, they have the unintended side-effect of precluding the joy of anticipation. Younger children may also be more prone to magical thinking than older children and to have superstitious beliefs about the effects of intention or anticipation on future outcomes (McLeish, 1984), such as the notion that looking forward to a positive event tempts fate and thereby jinxes the outcome. Such beliefs might make children more willing to savor prospectively as they grow older.

\subsection{Distinguishing temporal capacities to savor}

Although children develop the ability to savor the moment, reminisce about the past, and anticipate the future by early childhood, the ability to differentiate these capacities develops in late adolescence. Using the Children's Savoring Beliefs Inventory (CSBI) with children ages 10 to 13 (i.e., stage of concrete operations) reveals that unlike college students and older adults (i.e., stage of formal operations), preadolescents hold a unitary conception of their capacity to savor positive experiences and do not distinguish among their abilities to savor prospectively through anticipation, concurrently in the moment, or retrospectively through reminiscence (Bryant \& Veroff, 2007). Cross-validating research with older populations, girls report higher CSBI total scores than do boys across all four ages. In other words, compared to boys, girls generally perceive themselves as better able to enjoy positive experience. Thus, gender differences in perceived savoring ability emerge as early as 10 years old. Considered together, these data suggest that children make judgments of their capacity to savor their lives, but that these evaluations are less differentiated with respect to time than are adults' self-evaluations. But the age at which children's awareness of their capacity to savor first develops remains is yet to be determined.

\subsection{The development of specific savoring processes}

Savoring processes that involve basic emotions, such as joy or wonder, should emerge earlier in life than savoring processes that involve self-conscious, higher-order positive emotions, such as pride or gratitude, which develop later. Because infants' earliest facial expressions of enjoyment relate to physical pleasure (Sullivan \& Lewis, 2003), we might expect luxuriating to be the first savoring process to develop. Unlike the savoring process of basking in the pride of accomplishment, the process of mindfully appreciating physical pleasure does not require the experience of self-referent positive emotion. The basic emotion of joy typically emerges within the first nine months of life, whereas the high-order emotion of pride does not emerge until about age 3 (Tracy \& Robin, 2007). Likewise, young children seem to have an innate sense of awe and wonder in relation to the world around them - something adults often seem to lose and long to regain. The capacity to experience gratitude, on the other hand, does not fully develop until middle childhood, between ages 7 and 10 (Peterson \& Seligman, 2004).

Thus, based on current understanding of cognitive and emotional development, we can speculate about the typical sequence in the development of children's capacities to engage in specific types of savoring processes. Along these lines, we propose that children first acquire the abilities to savor through luxuriating and marveling, followed later by the ability to bask in the pride of accomplishment, and finally the ability to savor through thanksgiving. In the same 
vein, we would expect children to report hedonic savoring experiences involving positive feelings before they report eudaimonic savoring experiences involving meaning and purpose.

\subsection{Future directions for developmental research on savoring}

Current measurement tools are inadequate for developmental research aimed at identifying children's earliest forms of savoring. Existing self-report measures of savoring responses, such as the Ways of Savoring Checklist (WOSC; Bryant \& Veroff, 2007), have been designed and validated for use with adults. Although readability statistics reveal that the wording of the WOSC items is at a reading-level appropriate for the typical 9-year-old, using the current instrument presents at least two potential problems. First, if children younger than age 9 cannot comprehend the WOSC items, then researchers cannot use the WOSC to determine whether initial savoring responses emerge before age 9. Second, children may be capable of savoring positive experiences before they have the cognitive skills necessary to describe such experiences on a self-report questionnaire. These psychometric limitations suggest that pinpointing the age at which savoring first emerges may require researchers first to identify the precise neurological profiles associated with specific savoring processes and responses in adults, and then to determine the age at which these profiles first appear in children. Ultimately, such neurological profiles might well provide the "gold standard" for future work aimed at establishing the criterion validity of new measures of savoring responses, savoring beliefs, and actual savoring capacities.

\subsection{Savoring in older age}

Emerging evidence supports the notion that people's capacity to savor the moment increases later in life. Recent results from over 340,000 telephone interviews with individuals in the United States reveal that wellbeing, especially positive emotions, steadily increases from the age of 50 (Stone, Schwartz, Broderick, \& Deaton, 2010). Over the adult life-span, from 18 to 85 years of age, the trajectory of individuals' appraisals of their happiness resembles a " $U$ " -it begins high, dips from the late 30s until age 50, and then begins to climb, until by age 80 individuals have exceeded all reports of happiness at younger ages. Age-related increases in happiness may reflect an enhanced ability to savor the moment in older age that results from the perception that one's time is limited, which produces a heightened focus on current feelings (Carstensen, Fung, \& Charles, 2003). Consistent with this reasoning, Carstensen et al. (2003) have argued that, "it is precisely a sense of anticipated ending that makes old age emotionally meaningful. When emotional goals weigh more heavily than knowledge-related goals, people have the time to savor the moment, focus on the present, and derive emotional meaning" ( $\mathrm{p}$. 119). These conclusions are also consistent with Kurtz's (2008) experimental evidence that becoming more aware of the approaching end of an experience can boost one's appreciation of it. Harkening back to children's early absorption in spontaneous enjoyment, we suggest that people are most capable of savoring the moment during the early and late stages of their life.

Supporting the adaptive benefits of savoring, there is prospective evidence that positive emotions not only protect individuals from physical decline in old age (Ostir, Markides, Black, \& Goodwin, 2000), but also increase longevity (Danner, Snowdon, \& Friesen, 2001). Thus, savoring may ultimately optimize both the quality and quantity of life. As people age and their physical and cognitive capacities decline, special challenges emerge with respect to savoring. Older adults may no longer be able, or motivated, to savor the same experiences as when they were younger, nor may they be able to savor the same experiences in the same ways. This reasoning suggests that having a more diverse repertoire of savoring responses may enhance 
people's capacity to adapt more effectively to aging. A better understanding of the impact of aging on savoring (and of savoring on aging) would enable practitioners to develop effective interventions aimed at helping adults sustain the capacity to savor positive experience in old age. Much work remains in building a formal life-span developmental model of savoring.

\section{Conclusion}

In this paper, we have outlined three important, unsolved questions with respect to savoringnamely, what are its neuropsychological foundations, how can we study its role as a mediator of positive emotions during ongoing experience, and how does it develop across the lifespan? Through this endeavor, we hope to guide and encourage future work aimed at advancing our understanding of these key issues. We note that solving each of these tricky puzzles requires not only new theoretical frameworks, but also new ways to assess cognition and emotion. As has been the case in so many scientific areas, including the study of coping, conceptual progress often stems from crucial advances in measurement, which make it possible to test innovative hypotheses, and develop and refine new theoretical models. Thus, as Cattell (1893) wisely observed long ago, "the history of measurement is the history of science" (p. 316). For, unless one can measure the underlying phenomena of interest, it is impossible to conduct empirical research and advance knowledge. Certainly, this same progression must also occur in the study of savoring, as the development of new methods of assessment will enable theorists and researchers to solve thorny problems that no one has ever addressed.

Clearly, there are many other worthwhile areas of exploration within the general topic of savoring that we have not addressed here. Some of these additional savoring-related areas that are particularly ripe for future investigation include cultural differences and similarities, relationships with negative emotions and outcomes, intervention efforts, and evolutionary implications. It is our fondest hope that this paper will encourage readers to pursue work on savoring along many different lines in the years ahead.

\section{Acknowledgements}

The authors would like to thank Dr. Paul Jose for helpful feedback and advice on an earlier draft of this manuscript. We would also like to thank Andrew Swift (MS CMI) at www.swiftillustration.com for his image of the natural brain; it provided us with an excellent canvas to highlight regions we speculate are associated with savoring.

\section{Authors}

Fred B. Bryant

Loyola University Chicago

fbryant@luc.edu

Erica D. Chadwick

Victoria University of Wellington

Katharina Kluwe

Loyola University Chicago

\section{References}

Addis, D. R., Wong, A. T., \& Schacter, D. L. (2007). Remembering the past and imagining the future: Common and distinct neural substrates during event construction and elaboration. Neuropsychologia, 45, 13631377. http://dx.doi.org/10.1016/j.neuropsychologia.2006.10.016 
Adolphs, R. (2001). The neurobiology of social cognition. Current Opinions in Neurobiology, 11, $231-239$. http://dx.doi.org/10.1016/S0959-4388(00)00202-6

Atance, C. M., \& O'Neill, D. K. (2001). Episodic future thinking. Trends in Cognitive Sciences, 5, 533-539. http://dx.doi.org/10.1016/S1364-6613(00)01804-0

Bailenson, J. N., Pontikakis, E. D., Mauss, I. B., Gross, J. J., Jabon, M. E., Hutcherson, C. A. C., Nass, C., \& John, O. (2008). Real-time classification of evoked emotions using facial feature tracking and physiological responses. International Journal of Human-Computer Studies, 66, 303-317. http://dx.doi.org/10.1016/j.ijhcs.2007.10.011

Band, E. B., \& Weisz, J. R. (1990). Developmental differences in primary and secondary control coping and adjustment to juvenile diabetes. Journal of Clinical Child Psychology, 19, 150-158. http://dx.doi.org/10.1207/s15374424jccp1902 7

Baron, R. M., \& Kenny, D. A. (1986). The moderator-mediator variable distinction in social psychological research: Conceptual, strategic and statistical considerations. Journal of Personality and Social Psychology, 51, 1173-1182. http://dx.doi.org/10.1037/0022-3514.51.6.1173

Borod, J. (2000). (Ed.) The neuropsychology of emotion. New York: Oxford University Press.

Botzung, A., Denkova, E., \& Manning, L. (2008). Experiencing past and future personal events: Functional neuroimaging evidence on the neural bases of mental time travel. Brain and Cognition, 66, 202-212. http://dx.doi.org/10.1016/j.bandc.2007.07.011

Bretherton, I., McNew, S., \& Beeghly-Smith, M. (1981). Early person knowledge as expressed in gestural and verbal communication: When do infants acquire a "theory of mind"? In M. E. Lamb \& L. R. Sherrod (Eds.), Infant social cognition (pp. 333-373). Hillsdale, NJ: Erlbaum.

Bronfenbrenner, U., \& Morris, P. M. (2005). The bioecological model of human development. In R.M. Lerner and W. Damon (Eds.), Handbook of child psychology (6 ${ }^{\text {th }}$ ed.), (pp. 793-828). Hoboken, NJ: Wiley.

Brown, G. K., \& Nicassio, P. M. (1987). Development of a questionnaire for the assessment of active and passive coping strategies in chronic pain. Pain, 31, 53-64.

Bryant, F. B. (1989). A four-factor model of perceived control: Avoiding, coping, obtaining, and savoring. Journal of Personality, 57, 773-797. http://dx.doi.org/10.1111/j.1467-6494.1989.tb00494.x

Bryant, F. B. (2003). Savoring Beliefs Inventory (SBI): A scale for measuring beliefs about savouring. Journal of Mental Health, 12, 175-196. http://dx.doi.org/10.1080/0963823031000103489

Bryant, F. B., Ericksen, C. L., \& DeHoek, A. H. (2008). Savoring. In S.J. Lopez (Ed.), Encyclopedia of positive psychology, Vol. 2 (pp. 857-859). New York: Wiley/Blackwell.

Bryant, F. B., \& Veroff, J. (2007). Savoring: A new model of positive experience. Mahwah, NJ: Lawrence Erlbaum.

Burgdorf, J., \& Panksepp, J. (2006). The neurobiology of positive emotions. Neuroscience and Biobehavioral Reviews, 30, 173-187. http://dx.doi.org/10.1016/j.neubiorev.2005.06.001

Carroll, J. J., \& Steward, M. S. (1984). The role of cognitive development in children's understandings of their own feelings. Child Development, 55, 1486-1492.

Carstensen, L. L., Fung, H. H., \& Charles, S. T. (2003). Socioemotional selectivity theory and the regulation of emotion in the second half of life. Motivation and Emotion, 27, 103-123. http://dx.doi.org/10.1023/A:1024569803230

Cattell, J. M. (1893). Mental measurement. Philosophical Review, 2, 316-332.

Chadwick, E. D., \& Jose, P. E. (2010, June). Savoring: A path to greater well-being in adolescence. Paper presented at the 5th European Conference on Positive Psychology, Copenhagen, Denmark.

Coan, J. A., \& Allen, J. J. B. (2004). Frontal EEG asymmetry as a moderator and mediator of emotion. Biological Psychology, 67, 7-49. http://dx.doi.org/10.1016/j.biopsycho.2004.03.002

Compas, B. E. (1998). An agenda for coping research and theory: Basic and applied developmental issues. International Journal of Behavioral Development, 22, 231-237. http://dx.doi.org/10.1080/016502598384351

Cowie, R., \& Cornelius, R. R. (2003). Describing the emotional states that are expressed in speech. Speech Communication, 40, 5-32. http://dx.doi.org/10.1016/S0167-6393(02)00071-7

Damasio, A., Garbowski, T. J., Bechara, A., Damasio, H., Ponto, L. L. B., Parvizi, J., \& Hichwa, R. D. (2000). Subcortical and cortical activity during the feeling of self-generated emotions. Nature Neuroscience, 3, 10491056. http://dx.doi.org/10.1038/79871

Danner, D. D., Snowdon, D. A., \& Friesen, W. V. (2001). Positive emotions in early life and longevity: Findings from the nun study. Journal of Personality and Social Psychology, 80, 804-813. http://dx.doi.org/10.1037/00223514.80.5.804 
Ekman, P. \& Friesen, W. V. (1978). Facial action coding system: A technique for the measurement of facial movement. Palo Alto, CA: Consulting Psychologists Press.

Ericsson, K. A., \& Simon, H. A. (1993). Protocol analysis: Verbal reports as data (revised ed.). Cambridge, MA: The MIT Press.

Fivush, R., Haden, C. A., \& Reese, E. (1996). Remembering, recounting, and reminiscing: The development of autobiographical memory in social context. In D. C. Rubin (Ed.), Remembering our past: Studies in autobiographical memory (pp. 341-359). New York: Cambridge University Press.

Hamann, S. B., Ely, T. D., Hoff man, J. M., \& Kilts, C. D. (2002). Ecstasy and agony: Activation of the human amygdala in positive and negative emotion. Psychological Science, 13, 135-141. http://dx.doi.org/10.1111/1467-9280.00425

Harris, P. L., Guz, G. R., Lipian, M. S., \& Man-Shu, Z. (1985). Insight into the time course of emotion among Western and Chinese children. Child Development, 56, 972-988.

Harris, P. L., \& Lipian, M. S. (1989). Understanding emotion and experiencing emotion. In C. Saarni, \& P. L. Harris (Eds.), Children's Understanding of Emotion (pp. 241-258). Cambridge: Cambridge University Press.

Holmbeck, G. H. (1997). Toward terminological, conceptual, and statistical clarity in the study of mediators and moderators: Examples from the child-clinical and pediatric psychology literatures. Journal of Consulting and Clinical Psychology, 65, 599-610. http://dx.doi.org/10.1037/0022-006X.65.4.599

Hughes, F. P. (2010). Children, play, and development (4 $4^{\text {th }}$ ed.). Thousand Oaks, CA: Sage.

Ikemto, S. (2010). Brain reward circuitry beyond the mesolimbic dopamine system: A neurobiological theory. Neurosciences and Biobehavioural Reviews, 35, 129-150. http://dx.doi.org/10.1016/j.neubiorev.2010.02.001

Inhelder, B., \& Piaget, J. (1958). The growth of logical thinking from childhood to adolescence: An essay on the construction of formal operational structures. New York: Basic Books. http://dx.doi.org/10.1037/10034-000

James, L. R., \& Brett, J. M. (1984). Mediators, moderators, and tests for mediation. Journal of Applied Psychology, 69, 307-321. http://dx.doi.org/10.1037/0021-9010.69.2.307

Keefe, F. J., Brown, G. K., Wallston, K. A., \& Caldwell, D. S. (1989). Coping with rheumatoid arthritis pain: Catastrophizing as a maladaptive strategy. Pain, 37, 51-56.

Knutson, B., Adams, C., Fong, G., \& Hommer, D. (2001). Anticipation of monetary reward selectively recruits nucleus accumbens. Journal of Neuroscience, 21 (RC159), 1-5.

Kringelbach, M. L., \& Berridge, K. C. (2009). Towards a functional neuroanatomy of pleasure and happiness. Trends in Cognitive Sciences, 13, 479-487. http://dx.doi.org/10.1016/j.tics.2009.08.006

Kurtz, J. L. (2008). Looking to the future to appreciate the present: The benefits of perceived temporal scarcity. Psychological Science, 19, 1238-1241. http://dx.doi.org/10.1111/j.1467-9280.2008.02231.x

Lambie, J. A., \& Marcel, A. J. (2002). Consciousness and the varieties of emotion experience: A theoretical framework. Psychological Review, 109, 219-259. http://dx.doi.org/10.1037/0033-295X.109.2.219

Larsen, R. J., \& Fredrickson, B. K. (1999). Measurement issues in emotion research. In D. Kahneman, E. Diener, \& N. Schwarz (Eds.), Well-Being: The Foundations of Hedonic Psychology (pp. 40-60). New York: Russell Sage Foundation.

Lazarus, R. S., \& Folkman, S. (1984). Stress, appraisal, and coping. New York: Springer.

Lezak, M. D., Howieson, D. B., Loring, D. W., Hannay, J. H., \& Fischer, J. S. (2004). Neuropsychological assessment (4 ${ }^{\text {th }}$ ed.). New York: Oxford University Press.

Light, S. N., Coan, J. A., Frye, C., Goldsmith, H. H., \& Davidson, R. J. (2009). Dynamic variation in pleasure in children predicts nonlinear change in lateral frontal brain electrical activity. Developmental Psychology, 45 , 525-533. http://dx.doi.org/10.1037/a0014576

MacCorquodale, K., \& Meehl, P. E. (1948). On a distinction between hypothetical constructs and intervening variables. Psychological Review, 55, 95-107. http://dx.doi.org/10.1037/h0056029

MacKinnon, D. P. (2000). Contrasts in multiple mediator models. In J. S. Rose, L. Chassin, C. C. Presson, S. J. Sherman (Eds.), Multivariate applications in substance use research: New methods for new questions (pp. 141160). Mahwah, NJ: Lawrence Erlbaum.

MacKinnon, D. P., \& Fairchild, A. J. (2008). Current directions on mediation analysis. Current Directions in Psychological Science, 18, 16-20. http://dx.doi.org/10.1111/j.1467-8721.2009.01598.x

MacKinnon, D. P., Fairchild, A. J., \& Fritz, M. S. (2007). Mediation analysis. Annual Review of Psychology, 58, 593-614. http://dx.doi.org/10.1146/annurev.psych.58.110405.085542

MacLean, P. D. (1990). The triune brain in evolution: Role in paleocerebral functions. New York: Springer. 
Matsunaga, M., Isowa, T., Kimura, K., Miyakoshi, M., Kanayama, N., Murakami, H., Fukuyama, S., Shinoda, J., Yamada, J., Konagaya, T., Kaneko, H., \& Ohira, H. (2009). Associations among positive mood, brain, and cardiovascular activities in an affectively positive situation. Brain Research, 1263, 93-103. http://dx.doi.org/10.1016/j.brainres.2009.01.027

McLeish, J. (1984). Children's superstitions. Canadian Journal of Education, 9, 425-436.

Mehl, M. R., Vazire, S., Holleran, S. E., \& Clark, C. S. (2010). Eavesdropping on happiness: Well-being is related to having less small talk and more substantive conversations Psychological Science, 21, 539-541. http://dx.doi.org/10.1177/0956797610362675

Melendez, J. C., \& McCrank, E. (1993). Anxiety-related reactions associated with magnetic imaging examinations. Journal of the American Medical Association, 270, 745-747.

Mischel, W., Shoda, Y., \& Rodriguez, M. L. (1989). Delay of gratification in children. Science, $244,933-938$. http://dx.doi.org/10.1126/science.2658056

Moos, R. H, \& Schaefer, J. A. (1991). Coping resources and processes: Current concept s and measures. In L. Goldberger \& S. Breznitz, Eds., Handbook of stress: Theoretical and clinical aspects (2nd ed.) (pp. 234-257). New York: Free Press.

Moser, E. I., Kropff, E., \& Moser, M. B. (2008). Place cells, grid cells, and the brain's spatial representation system. Annual Review of Neuroscience, 31, 68-89. http://dx.doi.org/10.1146/annurev.neuro.31.061307.090723

Olivier, E., Pouget, A., \& Duhamel, J. R. (2005). Reference frames for representing visual and tactile locations in the parietal cortex. Nature Neuroscience, 8, 941-949.

Ostir, G. V., Markides, K. S., Black, S. A., \& Goodwin, J. S. (2000). Emotional well-being predicts subsequent functional independence and survival. Journal of the American Geriatrics Society, 48, 473-478.

Paradiso, S., Johnson, D. L., Andreasen, N. C., O’Leary, D. S., Watkins, G. L., Ponto, L. L. B., \& Hichwa, R. D. (1999). Cerebral blood flow changes associated with attribution of emotional valence to pleasant, unpleasant, and neutral visual stimuli in a PET study of normal subjects. American Journal of Psychiatry, 156, 1618-1629.

Peterson, C., \& Seligman, M. E. P. (2004). Character strengths and virtues: A handbook and classification. Washington, DC: American Psychological Association.

Phan, K. L., Wager, T. D., Taylor, S. F., \& Liberzon, I. (2004). Functional neuroimaging studies of human emotions. CNS Spectrums, 9, 258-266.

Preacher, K. J., \& Hayes, A. F. (2008). Asymptotic and resampling strategies for assessing and comparing indirect effects in multiple mediator models. Behavior Research Methods, 40, 879-891. http://dx.doi.org/10.3758/BRM.40.3.879

Preacher, K. J., Rucker, D. D., \& Hayes, A. F. (2007). Assessing moderated mediation hypotheses: Theory, methods, and prescriptions. Multivariate Behavioral Research, 42, 185-227.

Preacher, K. J., Zyphur, M. J., \& Zhang, Z. (2010). A general multilevel SEM framework for assessing multilevel mediation. Psychological Methods, 15, 209-233. http://dx.doi.org/10.1037/a0020141

Quoidbach, J., Berry, E. V., Hansenne, M., \& Mikolajczak, M. (2010). Positive emotion regulation and wellbeing: Comparing the impact of eight savoring and dampening strategies. Personality and Individual Differences, 49, 368-373. http://dx.doi.org/10.1016/j.paid.2010.03.048

Reese, E., Haden, C. A., \& Fivush, R. (1993). Mother-child conversations about the past: Relationships of style and memory over time. Cognitive Development, 8, 403-430. http://dx.doi.org/10.1016/S0885-2014(05)80002-4

Reiser, M. F., Semmler, W., \& Hricak, H. (2008). Magnetic resonance tomography. New York: Springer. http://dx.doi.org/10.1007/978-3-540-29355-2

Rolls, E. T. (2006). Brain mechanisms underlying flavour and appetite. Philosophical Transactions of the Royal Society of London, Series B: Biological Sciences, 361,1123-1136. http://dx.doi.org/10.1098/rstb.2006.1852

Roth, S., \& Cohen, L. J. (1986). Approach, avoidance, and coping with stress. American Psychologist, 41, 813-819. http://dx.doi.org/10.1037/0003-066X.41.7.813

Schooler, J. W., Ariely, D., \& Loewenstein, G. (2003). The pursuit and assessment of happiness may be selfdefeating. In I. Brocas \& J. D. Carrillo (Eds.), The psychology of economic decisions. Volume 1: Rationality and well-being (pp. 41-70). New York: Oxford University Press.

Seidner, L. B., Stipek, D. J., \& Feshbach, N. D. (1988). A developmental analysis of elementary school-aged children's concepts of pride and embarrassment. Child Development, 59, 367-377. 
Shrout, P. E., \& Bolger, N. (2002). Mediation in experimental and nonexperimental studies: New procedures and recommendations. Psychological Methods, 7, 422-445. http://dx.doi.org/10.1037/1082-989X.7.4.422

Spencer, S. J., Zanna, M. P., \& Fong, G. T. (2005). Establishing a causal chain: Why experiments are often more effective than mediational analyses in examining psychological processes. Journal of Personality and Social Psychology, 89, 845-851. http://dx.doi.org/10.1037/0022-3514.89.6.845

Spinrad, T. L., Stifter, C. A., Donelan-McCall, N., \& Turner, L. (2004). Mothers' regulation strategies in response to toddlers' affect: Links to later emotion self-regulation. Social Development, 13, 40-55. http://dx.doi.org/10.1111/j.1467-9507.2004.00256.x

Stern, D. N., Hofer, L., Haft, W., \& Dore, J. (1985). Affect attunement: The sharing of feeling states between mother and infant by means of intermodal fluency. In T. M. Field, \& N. A. Fox (Eds.), Social perception in infants (pp. 249-268). Norwood, NJ: Ablex.

Stone, A., Schwartz, J. E., Broderick, J. E., \& Deaton, A. (2010). A snapshot of the age distribution of psychological well-being in the United States. Proceedings of the National Academy of Sciences, 107, 99859990. http://dx.doi.org/10.1073/pnas.1003744107

Suddendorf, T., \& Corballis, M. C. (2007). The evolution of foresight: What is mental time travel, and is it unique to humans? Behavioral and Brain Sciences, 30, 299-313. http://dx.doi.org/10.1017/S0140525X07001975

Sullivan, M. W., \& Lewis, M. (2003). Emotional expressions of young infants and children: A practitioner's primer. Infants and Young Children, 16, 120-142. http://dx.doi.org/10.1097/00001163-200304000-00005

Takahashi, H., Matsuura, M., Koeda, M., Yahata, N., Suhara, T., Kato, M., \& Okubo, Y. (2008). Brain activations during judgments of positive self-conscious emotion and positive emotion: Pride and joy. Cerebral Cortex, 18, 898-903. http://dx.doi.org/10.1093/cercor/bhm120

Taylor, A. B., MacKinnon, D. P., \& Tein, J.-Y. (2008). Tests of the three-path mediated effect. Organizational Research Methods, 11, 241-269. http://dx.doi.org/10.1177/1094428107300344

Terwogt, M. M., Schene, J., \& Harris, P. L. (1986). Self-control of emotional reactions by young children. Journal of Child Psychology and Psychiatry, 27, 357-366. http://dx.doi.org/10.1111/j.1469-7610.1986.tb01838.x

Thompson, R. A. (1990). Emotion and self-regulation. In R. A. Thompson (Ed.), Socioemotional development: Nebraska symposium on motivation (Vol. 36, pp. 367-467). Lincoln, NE: University of Nebraska Press.

Thompson, R.A. (1991). Emotional regulation and emotional development. Educational Psychology Review, 3, 269-307. http://dx.doi.org/10.1007/BF01319934

Tomarken, A. J., Davidson, R. J., \& Henriques, J. B. (1990). Resting frontal brain asymmetry predicts affective responses to films. Journal of Personality and Social Psychology, 59, 791-801. http://dx.doi.org/10.1037/0022$\underline{3514.59 .4 .791}$

Tomarken, A. J., Davidson, R. J., Wheeler, R. E., \& Doss, R. C. (1992). Individual differences in anterior brain asymmetry and fundamental dimensions of emotion. Journal of Personality and Social Psychology, 62, 676687. http://dx.doi.org/10.1037/0022-3514.62.4.676

Tomkins, S. (1962). Affect, imagery, consciousness (Volume I: The positive affects). New York: Springer.

Tracy, J. L. \& Robin, R. W. (2007). The nature of pride. In J. L. Tracy, R. W. Robins, \& J. P. Tangney (Eds.), The self-conscious emotions: Theory and research (pp. 263-282). New York: Guilford Press.

Tronick, E. Z., Cohn, J., \& Shea, E. (1986). The transfer of affect between mothers and infants. In T. B. Brazelton \& M. W. Yogman, (Eds.), Affective development in infancy (pp. 11-25). Norwood, NJ: Ablex.

Vanhaudenhuyse, A., Demertzi, Schabus, M., Noirhomme, Q., Bredart, S., Boly, M., Phillips, C., Soddu, A., Luxen, A., Moonen, G., \& Laureys, S. (2011). Two distinct neuronal networks mediate the awareness of environment and of self. Journal of Cognitive Neuroscience, 23, 570-578.

http://dx.doi.org/10.1162/jocn.2010.21488

Woltering, S. \& Lewis, M. D. (2009). Developmental pathways of emotion regulation in childhood: A neuropsychological perspective. Mind, Brain, and Education, 3(3), 160-169. http://dx.doi.org/10.1111/j.1751-228X.2009.01066.x

Wood, J. V., Heimpel, S. A., \& Michela, J. L. (2003). Savoring versus dampening: Self-esteem differences in regulating positive affect. Journal of Personality and Social Psychology, 85, 566-580.

http://dx.doi.org/10.1037/0022-3514.85.3.566 